\title{
Scintigraphic assessment of osteoarthritis of the knee joint
}

\author{
Fiona McCrae, Jennie Shouls, Paul Dieppe, Iain Watt
}

\begin{abstract}
Clinical, radiographic, and scintigraphic abnormalities of the knee joint have been correlated in a cross sectional study of 100 patients with osteoarthritis. The group comprised 73 women and 27 men with a mean age of 65.7 years. One hundred and ninety one of the 200 knees had clinical (175) or radiographic (185) evidence of osteoarthritis, or both (161). Scintigraphic images of the knees were obtained 4-5 minutes (early phase) and 2.5 3.5 hours (late phase) after intravenous injection of $600 \mathrm{mBq}$ of technetium- $99 \mathrm{~m}$ diphosphonate. Abnormal images were recorded in 162 knees $(81 \%)$, and six different patterns were detected. Generalised isotope retention around the knee (early or late phase) was less common than focal areas of uptake around the joint margin (early or late phase) or in the patella or subchondral bone (late phase). Some knees with abnormal scans were normal on radiography $(n=7)$, or vice versa $(n=21)$. Different scan patterns correlated with different clinical and radiographic features: the generalised pattern correlated with pain (odds ratio $(O R)=45 \cdot 1)$ and osteophytes $(O R=48 \cdot 3)$; joint line retention correlated with subchondral bone sclerosis on radiography $(\mathrm{OR}=62 \cdot 1)$; and subchondral bone retention correlated with more severe radiographic changes. It is concluded that different patterns of scintigraphic abnormality reflect various aspects of the disease process of osteoarthritis.
\end{abstract}

(Ann Rheum Dis 1992; 51: 938-942)

Osteoarthritis of the knee joint is one of the most common rheumatic diseases in the community with an estimated prevalence of $2 \cdot 4 \%$ in adult men and $3 \cdot 0 \%$ in women. ${ }^{12}$ It is a heterogeneous disease with a variable outcome, ${ }^{34}$ but relatively little is known about the processes taking place. ${ }^{5}$ Current means of assessment are limited to crude measures of outcome such as pain, functional impairment, and the extent of anatomical changes seen on a radiograph. There are no established methods of assessing the disease process.

Technetium labelled diphosphonates are widely used as bone scanning agents to detect areas of increased bone activity. ${ }^{6}$ They often localise around osteoarthritic ioints. ${ }^{78}$ It has been suggested that these agents are taken up by areas of active subchondral bone change in osteoarthritis as well as in areas of synovitis, 910 thus providing a potential means of assessing two important aspects of the disease. Previous investigations of osteoarthritis of the hand have shown that the bone scan can be abnormal in the absence of radiographic changes and that an abnormal scan is a predictor of subsequent radiological change. ${ }^{11} 12$ Osteoarthritic finger joints are too small to allow easy analysis of uptake in different areas of the joint and scans can only be graded as normal or abnormal.

\section{Patients and methods}

Local ethical committee approval was obtained for the study. One hundred patients over the age of 40 years were investigated. The subjects were recruited from a hospital based rheumatology clinic. All those thought to have osteoarthritis of one or both knees as their main rheumatological problem were referred to a special study clinic where they were reviewed by one of the authors (FM). Patients with clinical, laboratory, or radiographic evidence of an inflammatory arthropathy were rejected and the remainder were entered into the study subject to informed consent. Clinical data were recorded using a standard protocol. Demographic data obtained included the age, sex, duration of joint symptoms, height, weight, any previous knee trauma or surgery, and current treatment including walking aids. The pain (at rest and on use) and stiffness in each knee were recorded on a scale of 0-3 (none, mild, moderate, severe). Patients were asked to localise their pain to the medial, lateral, or anterior aspects of the knee. On examination bony and soft tissue swelling of each knee was recorded $(0-3)$, ligamentous instability and crepitus were noted as present or absent, and the range of knee flexion and any varus or valgus deformity recorded in degrees using a goniometer. Tenderness was recorded as present or absent on the joint line of the medial, lateral, and patellofemoral joints. Other joints were examined for evidence of osteoarthritis or another arthropathy.

Standard anteroposterior (standing) and lateral radiographs were obtained of both knees. Each of six different radiographic features were scored visually in each compartment (medial, lateral, and patellofemoral) on a scale of $0-2$ (absent, present, severe). The features recorded were joint space narrowing, subchondral sclerosis, cysts, osteophytosis, effusion, and bone destruction. Chondrocalcinosis and 'loose bodies' were also noted as present or absent.

Bone scintigraphy was peformed on the same day. A dose of $600 \mathrm{MBq}$ of technetium- $-99 \mathrm{~m}$ labelled hydroxymethylene diphosphonate was injected intravenously and the knees were
Bristol BS2 8HW,

I Watt

Correspondence to: Professor Dieppe. 
scanned using the same dedicated gamma camera in each patient. Two phases were recorded: the 'early' phase beginning at the time of injection and lasting until $200 \times 10^{6}$ counts had been collected (usually four to five minutes), and the 'late' phase obtained between 2.5 and 3.5 hours after injection. Only anteroposterior images were obtained in the early phase but both anteroposterior and lateral views were collected during the late phase scan. The analogue images were assessed visually and each compartment scored separately. Abnormal isotope retention was first recorded as present or absent in each compartment. If present the severity $(0-3)$ and pattern of the change were also recorded.

Scan abnormalities and patterns were correlated with the conventional clinical and radiological findings. Statistical analysis was performed using the $\chi^{2}$ test and calculation of the odds ratios of associations between different features.

\section{Results}

The 100 patients consisted of 73 women and 27 men with a mean age of $65 \cdot 7$ years and a mean duration of knee pain of $9 \cdot 1$ years. Seventeen subjects had a history of major trauma or previous surgery in the worst affected knee indicative of 'secondary' osteoarthritis. The remainder were classified as having 'primary' osteoarthritis; $92 \%$ of this group had symptoms in joint sites other than the knee and $65 \%$ were overweight or obese (index body mass $>25$ ). Sixty five were receiving analgesic or antiinflammatory drugs for their knee symptoms at the time of assessment and 46 patients were using walking aids (one stick in 34 patients).

Table 1 gives the symptoms and signs for each knee $(n=200)$. Twelve patients were free of pain at the time of the study, 19 had unilateral knee symptoms, and 69 had bilateral

Table 1 Main symptoms and signs of osteoarthritis in 200 knee joints examined in this study

\begin{tabular}{lll}
\hline Symptom/sign & $\begin{array}{l}\text { No (\%) of knees } \\
\text { in which } \\
\text { symptom/sign present }\end{array}$ & $\begin{array}{l}\text { Nowith severe } \\
\text { symptom/sign }\end{array}$ \\
\hline Knee pain & $157(79)$ & - \\
$\quad$ Use related pain & $140(70)$ & 58 \\
Rest pain & $67(34)$ & 4 \\
Inactivity stiffness & $134(67)$ & 39 \\
Morning stiffness & $126(63)$ & 35 \\
Soft tissue swelling & $106(53)$ & 42 \\
Bony swelling & $105(53)$ & 46 \\
Varus angulation & $63(32)$ & - \\
Valgus angulation & $19(10)$ & - \\
Fixed flexion deformity & $62(31)$ & - \\
Crepitus & $132(66)$ & - \\
\hline
\end{tabular}

Table 2 Occurrence of six different radiographic features of osteourthritis in each compartment of the 200 knee joints examined in this study. Some abnormality was seen in 176 $(88 \%)$ knees

\begin{tabular}{|c|c|c|c|}
\hline \multirow[t]{2}{*}{ Radiographic feature } & \multicolumn{2}{|l|}{ Compartment } & \multirow{2}{*}{$\begin{array}{l}\text { Patcllofemoral } \\
\text { joint }\end{array}$} \\
\hline & $\begin{array}{l}\text { Medial } \\
\text { tibiofemoral }\end{array}$ & $\begin{array}{l}\text { Lateral } \\
\text { tibio/emoral }\end{array}$ & \\
\hline $\begin{array}{l}\text { Joint space narrowing } \\
\text { Osteophytosis } \\
\text { Subchondral sclerosis } \\
\text { Subchondral cysts } \\
\text { Loss of cortical integrity } \\
\text { Attrition of bone }\end{array}$ & $\begin{array}{r}111 \\
100 \\
55 \\
6 \\
16 \\
16\end{array}$ & $\begin{array}{r}55 \\
112 \\
30 \\
6 \\
8 \\
3\end{array}$ & $\begin{array}{r}114 \\
125 \\
41 \\
25 \\
0 \\
0\end{array}$ \\
\hline
\end{tabular}

knee problems. Pain on use was the most common symptom and was severe in 58 knees. Most patients localised their pain to the medial (89) or anterior (57) part of the knee joint. A wide range of clinical abnormalities was recorded. Only 35 joints were considered normal. Crepitus and swelling were present in most, 63 had a deformity, and 47 were unstable. Joint tenderness was more common on the medial side of the joint (91 knees) than on the lateral side (41 knees). The mean (SD) haemoglobin concentration in the group was $135(16 \cdot 2) \mathrm{g} / \mathrm{l}$, the mean plasma viscosity 1.66 (normal $<1 \cdot 72$ ), and only four patients were seropositive for rheumatoid factor.

On examination of the radiographs, 91 of the 100 patients were thought to have unequivocal evidence of knee osteoarthritis, unilateral in six and bilateral in 85 patients. Of the nine patients without definite radiographic evidence of osteoarthritis, four had no knee pain at the time of the study, the remaining five had knee pain on use and abnormal physical signs, including knee joint crepitus. Table 2 shows that joint space narrowing and osteophytosis were the most common radiographic signs, and the medial tibiofemoral compartments were the most common sites of osteoarthritis.

Some abnormality on scinitigraphy was present in $162(81 \%)$ of the 200 knees examined. Review of the images obtained resulted in the recognition of two different patterns on the early phase and four different patterns on the late phase scan. These six patterns are illustrated in figs 1-6. Early phase images showed isotope

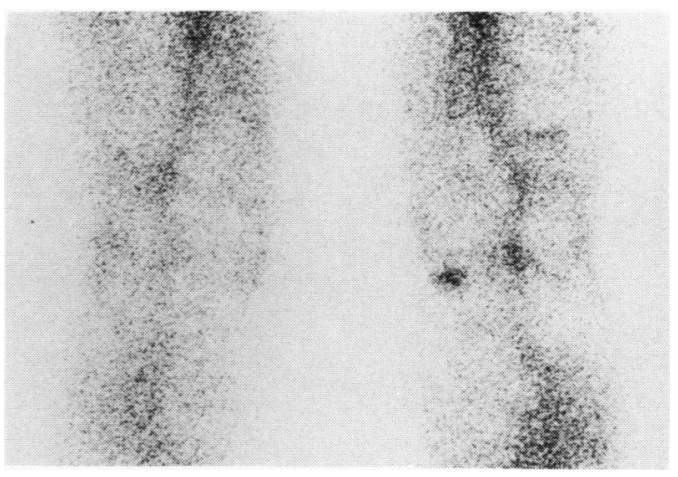

Figure 1 Early phase image showing isotope retention at the medial joint line.

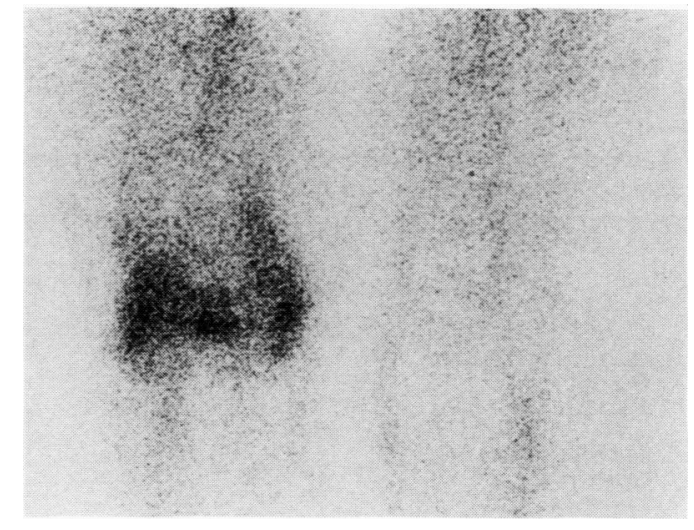

Figure 2 Early phase image showing isotope retention in a generalised distribution in a knee with active synovitis. 


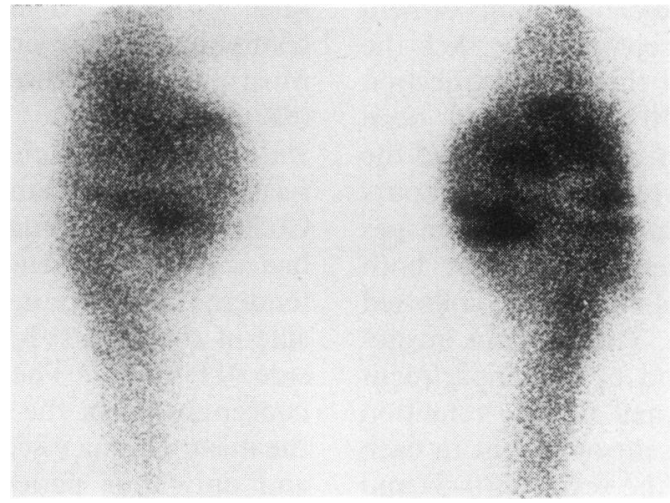

Figure 3 Late phase image showing isotope retention in the joint line, the 'tramline pattern'.

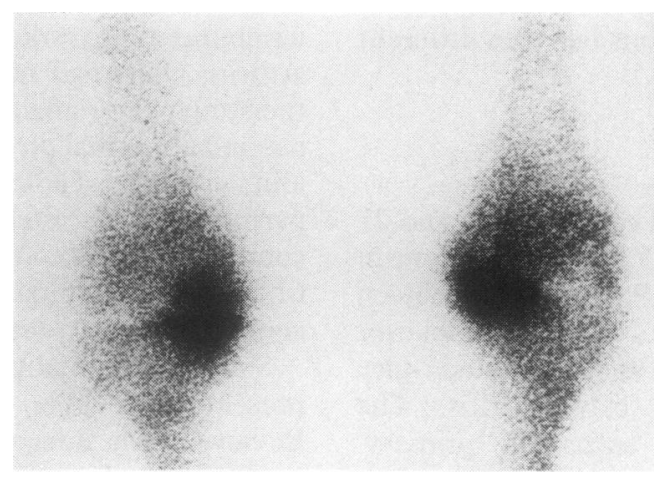

Figure 4 Late phase image showing isotope retention extending into the subchondral bone, the 'extended pattern'.

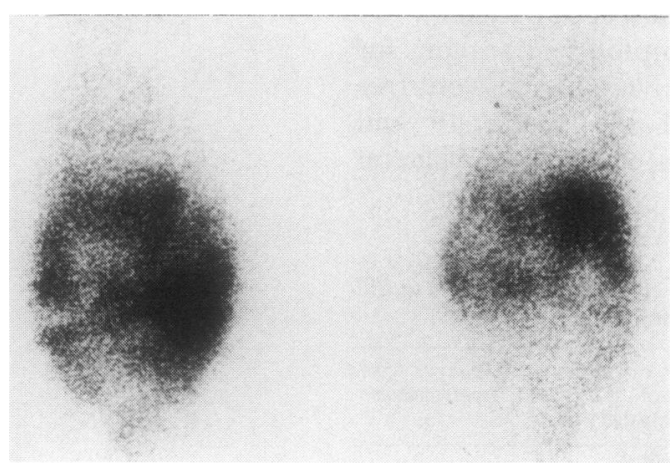

Figure 5 Late phase image showing widespread uptake around the joint, the 'generalised pattern', in addition to the extended pattern uptake in the medial compartment.

Table 3 Scintigraphic abnormalities in 200 knee joints examined in this study. Some abnormality was seen in $162(81 \%)$ knees

\begin{tabular}{|c|c|c|c|c|}
\hline \multirow[t]{2}{*}{ Scan abnormality } & \multicolumn{4}{|c|}{ Area of knee joint affected } \\
\hline & Generalised & $\begin{array}{l}\text { Medial } \\
\text { compartment }\end{array}$ & $\begin{array}{l}\text { Lateral } \\
\text { compartment }\end{array}$ & $\begin{array}{l}\text { Patcllo/emoral } \\
\text { joint }\end{array}$ \\
\hline $\begin{array}{l}\text { Early (perfusion) phase } \\
\text { Generalised } \\
\text { Localised (joint line) }\end{array}$ & 17 & $\overline{49}$ & $\overline{31}$ & $\overline{19}$ \\
\hline $\begin{array}{l}\text { Late (bone) phase } \\
\text { Generalised } \\
\text { Localised } \\
\text { Joint line } \\
\text { Extended } \\
\text { Patella }\end{array}$ & $\begin{array}{l}75 \\
- \\
=\end{array}$ & $\begin{array}{r}- \\
121 \\
22 \\
-\end{array}$ & $\begin{array}{r}- \\
54 \\
8 \\
-\end{array}$ & $\begin{array}{l}- \\
\frac{65}{45}\end{array}$ \\
\hline
\end{tabular}

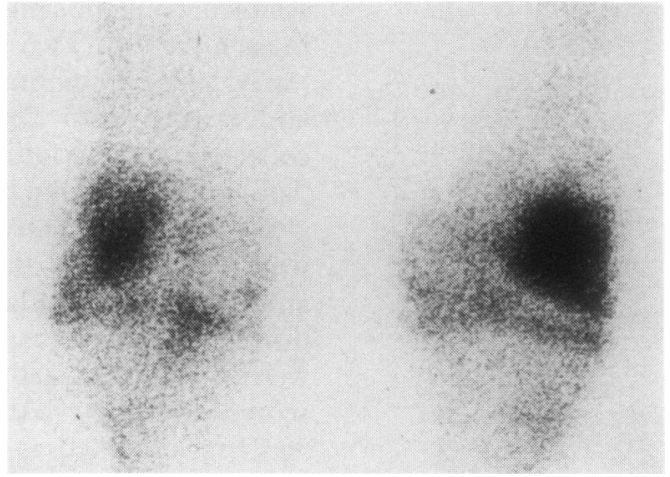

Figure 6 Late phase image showing isotope retention in both patellae, the 'hot patella', and joint line 'tramline' uptake.

retention either around the joint line or in a generalised distribution. Late phase isotope retention occurrred on the joint line (the 'tramline' pattern), in the subchondral bone ('extended' pattern), all round the joint ('generalised'), or was isolated to the patella (the 'hot patella'). These patterns were not mutally exclusive, some knees showing several different types of uptake in the different joint compartments and in the two phases of the scan. Table 3 gives the overall frequency of the different patterns of uptake. Joint line uptake was the most common finding and late phase retention was seen much more often than early phase abnormalities.

Correlations between clinical, radiographic, and scintigraphic changes have been made. Nine knees in six patients were considered normal on all three parameters. The remaining 191 knees had clinical (175) or radiographic (185) evidence

Table 4 Correlation between the presence or absence of clinical and scintigraphic abnormalities in 200 knee joints studied. All correlations were statistically significant on the $\chi^{2}$ test $(p<0.01)$

\begin{tabular}{|c|c|c|}
\hline \multirow[t]{2}{*}{ Clinical } & \multicolumn{2}{|l|}{ Scintigraphic } \\
\hline & Normal $(n=38)$ & Abnormal $(n=162)$ \\
\hline $\begin{array}{l}\text { Normal }(n=35) \\
\text { Abnormal }(n=165)\end{array}$ & $\begin{array}{l}15 \\
23\end{array}$ & $\begin{array}{r}20 \\
142\end{array}$ \\
\hline
\end{tabular}

Table 5 Correlation between the presence or absence of radiographic and scintigraphic abnormalities in 200 knee joints studied. All correlations were statistically significant on the $\chi^{2}$ test $(p<0.01)$

\begin{tabular}{llc}
\hline Radiographic & \multicolumn{2}{l}{ Scintigraphic } \\
\cline { 2 - 3 } & Normal $(n=38)$ & Abnormal $(n=162)$ \\
\hline Normal $(n=24)$ & 17 & 7 \\
Abnormal $(n=176)$ & 21 & 155
\end{tabular}

Table 6 Correlation between the presence or absence of clinical and radiographic abnormalities in 200 knee joints studied. All correlations were statistically significant on the $\chi^{2}$ test $(p<0 \cdot 01)$

\begin{tabular}{llc}
\hline Clinical & \multicolumn{2}{l}{ Radiographic } \\
\cline { 2 - 3 } & Normal $(n=24)$ & Abnormal $(n=176)$ \\
\hline $\begin{array}{ll}\text { Normal }(n=35) \\
\text { Abnormal }(n=165)\end{array}$ & 11 & 24 \\
\hline
\end{tabular}


Table 7 Positive relationships between the three common patterns of scintigraphic abnormality, and clinical and radiographic features of osteoarthritis of the knee joint. Values given are odds ratio (confidence intervals); the higher the odds ratio, the stronger the association

\begin{tabular}{|c|c|c|c|}
\hline \multirow{2}{*}{$\begin{array}{l}\text { Clinical radiographic } \\
\text { features of osteoarthritis }\end{array}$} & \multicolumn{3}{|c|}{ Scintigraphic patterns on late (bone phase) images } \\
\hline & $\begin{array}{l}\text { Generalised } \\
(n=75)\end{array}$ & $\begin{array}{l}\text { Joint line } \\
(n=220)\end{array}$ & $\begin{array}{l}\text { Extended } \\
\text { bone uptake } \\
(n=30)\end{array}$ \\
\hline $\begin{array}{l}\text { Pain }(n=157) \\
\text { Joint space narrowing }(n=280) \\
\text { Osteophytosis }(n=337) \\
\text { Sclerosis }(n=126)\end{array}$ & $\begin{array}{c}45 \cdot 1(6.07 \text { to } 335)^{*} \\
27 \cdot 2(3.63 \text { to } 204)^{*} \\
48.3(6.51 \text { to } 359)^{*} \\
9.99(4.8 \text { to } 20.8)\end{array}$ & $\begin{array}{c}3 \cdot 05(2 \cdot 14 \text { to } 4 \cdot 36) \\
13 \cdot 8(8 \cdot 43 \text { to } 22 \cdot 5) \\
5 \cdot 43(3 \cdot 49 \text { to } 8 \cdot 45) \\
62 \cdot 1(19 \cdot 1 \text { to } 202)^{*}\end{array}$ & $\begin{array}{r}3 \cdot 71(2 \cdot 26 \text { to } 6 \cdot 12) \\
47 \cdot 3(6 \cdot 38 \text { to } 352)^{4} \\
3.51(1.29 \text { to } 7 \cdot 34) \\
33.8(11.4 \text { (0 } 101)^{4}\end{array}$ \\
\hline
\end{tabular}

*Significant with $p<0.01$ using the $\chi^{2}$ test.

of osteoarthritis, or both (161). The scintigraphic abnormalities have been related to key clinical and radiographic changes in abnormal knees. Tables $4-6$ show that most knees had both radiographic and scintigraphic abnormalities, though knee joints were occasionally either radiographically positive and scan negative, or vice versa. Table 7 summarises the positive correlations found between different scintigraphic patterns and various clinical and radiographic changes.

It is apparent that the commonly observed uptake of isotope in a linear or joint line pattern correlates well with the presence of subchondral sclerosis on a radiograph. The less common extended pattern of uptake, in which isotope retention is seen in a large area of subchondral bone, was associated with more severely damaged knees, correlating with joint space narrowing and subchondral sclerosis. Conversely only the generalised pattern of uptake correlated significantly with any clinical feature, being associated with pain and with radiographic evidence of osteophytosis.

\section{Discussion}

Osteoarthritis is an enigmatic condition which remains poorly understood. ${ }^{13}$ It can be regarded as a mixture of damage to a joint and the reaction pattern induced by that damage. ${ }^{14}$ The pathological processes taking place include cartilage destruction, subchondral bone changes, and a variable degree of synovial reaction. ${ }^{15}$ The outcome of osteoarthritis is variable and can include extensive changes in the anatomy of the joint, pain (particularly on joint use), and disability resulting from pain, loss of joint movement and stability, and other changes. The visible outcomes tend to appear and change slowly, with a time course of many years. ${ }^{16}$ The combination of heterogeneity, slow change, and an absence of any way of measuring the disease processes makes it a difficult disease to investigate. ${ }^{17}$ The work reported here used scintigraphy as a means of assessing the disease process.

The study group consisted of 100 patients from a hospital rheumatology clinic thought to have osteoarthritis of the knee. At the time of the study several had become asymptomatic and a small number had no clinical or radiological evidence of osteoarthritis in either knee. Most, however, had abnormalities of one, or more often both, knees. There are no satisfactory criteria for making a diagnosis of knee osteoarthritis, ${ }^{18}$ though the combination of age, crepitus, swelling, and radiographic changes seen in most of our study group would clearly fulfil the controversial American Rheumatism Association criteria, ${ }^{19}$ as well as other suggested criteria. ${ }^{20} 21$ Most had joint space narrowing and subchondral bone changes in symptomatic knees; these signs are generally regarded as the cardinal features of osteoarthritis. ${ }^{18} 22$ It is unlikely that the group is representative of patients with osteoarthritis of the knee as it occurs in the community, but a wide range of disease severity was seen, and the age/sex distribution was similar to that found in other studies of this disease. ${ }^{23}$ Our patients varied from those with the minimum evidence of osteoarthritis to a number with severe joint damage resulting in the need for drugs and walking aids. We felt it appropriate to study such a wide spectrum of disease to investigate the part played by scintigraphy and the relation of the scan to other features of osteoarthritis.

The radiographic findings in addition to the demographic and clinical data are in keeping with previous studies of osteoarthritis. Most patients were women with a high incidence of obesity and osteoarthritis at other joint sites indicative of typical primary osteoarthritis. ${ }^{24}$ Pain on joint use, crepitus, swelling, and loss of movement are all common features of osteoarthritis of the knee, ${ }^{19}$ and were the most common clinical findings in this study. The radiographs showed the expected dominance of the medial and patellofemoral compartment changes, lateral disease being much less common. ${ }^{8}$ The finding that osteophytosis without joint space narrowing is common in the lateral compartment when other compartments have evidence of cartilage damage is a new observation. It may indicate a reaction to abnormal stresses on the lateral compartment consequent on medial compartment disease. The other main conclusion from the clinical and radiographic analysis is related to the wide variation in severity and combination of changes seen in osteoarthritis of the knee; it is clearly a heterogenous disease. ${ }^{17}$

It has been known for many years that bone scanning agents can localise to osteoarthritic joints. ${ }^{7}$ Experimental studies in animal models have shown that the isotope is taken up in areas of active subchondral bone and in growing osteophytes. ${ }^{25}$ Previous work in human osteoarthritis has shown that the technique may be of predictive value in hand disease, ${ }^{12}$ and that scintigraphy is a sensitive way of detecting disease at the knee joint. ${ }^{8}$ Different patterns of scan activity in osteoarthritis have not been described previously, however. This study clearly showed that a variety of different patterns of isotope uptake can be differentiated in osteoarthritis of the knee.

There was a reasonable correlation between the clinical and radiographic evidence of disease in one of the three different compartments of the knee, and the localisation of a scan abnormality. A few knees had radiographic evidence of osteoarthritis without any scan abnormality, however, and several compartments had scintigraphic changes only. This indicates that, as in hand joints, scintigraphy is providing a different 
type of information to that present on the radiograph.

The attempted correlation of scintigraphic, clinical, and radiographic abnormalities provides some clues to the possible significance of the different patterns of isotope retention. The common linear tramline or joint line pattern of uptake correlates well with subchondral sclerosis. It seems likely therefore that this represents active bone formation in osteoarthritis. There is some evidence that this pattern is also associated with active osteophyte formation as seen by magnetic resonance imaging, ${ }^{26}$ suggesting that it may detect growing (rather than mature) osteophyte in addition to changing subchondral bone. The less common extended pattern of isotope uptake in subchondral bone was associated with more severe radiographic damage and may be indicative of advanced changes or active disease progression. The generalised pattern of uptake may be of most clinical significance. Early generalised isotope retention reflects abnormal perfusion and is sensitive to intra-articular steroids ${ }^{27}$; it would therefore appear to reflect an inflammatory component of the disease. In this study, however, significant generalised perfusion phase uptake was only seen in 17 knees (9\%), making statistical correlations with other features difficult. The late generalised pattern was strongly associated with joint pain and with osteophytes, suggesting that this pattern (seen in $38 \%$ of knees) may also have direct relevance to doctors, perhaps reflecting some aspect of the process which associates with symptoms. ${ }^{28}$ The hot patella is sometimes seen as an incidental finding on bone scans performed for other reasons; it showed no apparent correlations with any clinical or radiographic features other than a possible association with cysts in the patella.

In conclusion it appears that the different scintigraphic patterns observed may reflect the activity of different aspects of the osteoarthritic process. Prospective studies and further correlations between different biochemical, clinical, and imaging abnormalities are being undertaken to define this further.

We thank the Special Trustees of the Former United Bristol Hospitals, and the Arthritis and Rheumatism Council for financial support. 1 Peyron J G. Osteoarthritis: the epidemiological viewpoint.
Clin Orthop 1986; 213: 113-9.
2 Hadler N M. Osteoarthritis as a public health problem. Clin Rherm Dis 1985; 11: 175-85.

3 Mankin H J, Brandt K D, Shulman L E. Workshop on etiopathogenesis of osteoarthritis: proceedings and recommendations. F R heumatol 1986; 13: 1130-60.

4 Moskowitz R W. Introduction. In: Moskowitz R W, Howel D S, Goldberg G M, Mankin H J (eds). Osteoarthritis: diagnosis and management. Philadelphia: Saunders, 1984: 1-6.

5 Hamerman D. The biology of osteoarthritis. N Engl f Med 1989; 320: 1322-30.

6 Fogelman I, ed. $99 \mathrm{~m}$ Tc diphosphonate uptake mechanism on bone. In: Bone scanning in clinical practice. Berlin, New York: Springer-Verlag, 1986: 7-17.

7 Hoffer P B, Genant H K. Radionuclide joint imaging. Semin Nucl Med 1976; 6: 121-37.

8 Thomas R H, Resnick D, Alazraki N P, et al. Compartment evaluation of osteoarthritis of the knee. A comparative study of available diagnostic modalities. Radiology 1975; 116: 585-94.

9 Rosenspire K C, Blau M, Kennedy A C, Green F A. Assessment and interpretation of radiopharmaceutical joint imaging in an animal model of arthritis. Arthritis Rheum 1981; $24: 711-6$.

10 Dick W C, Collins K E, Buchanan W. Clinical studies on inflammation in small diarthrodial joints. Clin Sci 1972; 38: 123-30.

11 Hutton C W, Higgs E R, Jackson P C, Watt I, Dieppe P A. ${ }^{99 m}$ Tc HMDP bone scanning in generalised arthritis. I Comparison of the standard radiograph and four hour bone scan image of the hand. Ann Rheum Dis 1986; 45: 617-22.

12 Hutton C W, Higgs E R, Jackson P C, Watt I, Dieppe P A ${ }_{99 \mathrm{~m}} \mathrm{~T} c \mathrm{HMDP}$ bone scanning in generalised arthritis. II The four hour bone scan image predicts radiographic change. Ann Rheum Dis 1986; 45: 622-6.

13 Dieppe P, Hutton C, Campion G. Osteoarthritis: progressive or controllable? Montreal, Chicago: Siebert \& McIntyre, 1986. (PharmaLibri Monographs in Medicine.)

14 Hutton C, Dieppe P. Genetics of osteoarthritis. Clin Rheumatol 1988; 2: 703-10.

15 Altman $R$, Gray $R$. Inflammation in osteoarthritis. Clin Rhuem Dis 1985; 11: 353-68.

16 Massardo L, Watt I, Cushnaghan J, Dieppe P. An eight year prospective study of osteoarthritis of the knee joint. Ann Rheum Dis 1989; 48: 893-7.

17 Bjelle A. On the heterogeneity of osteoarthritis. Clin Rheumatol 1983; 2: 111-3.

18 McAlindon T, Dieppe P. Osteoarthritis: definitions and criteria [editorial]. Ann Rheum Dis 1989; 48: 531-2.

19 Altman R, Asch E, Bloch D, et al. Development of criteria for the classification for the reporting of osteoarthritis: classification of osteoarthritis of the knee. Arthritis Rheum 1986; 29: $1039-49$.

20 Kellgren J H, Lawrence J S. Radiological assessment of osteoarthritis. Ann Rheum Dis 1957; 16: 494-501.

21 Altman R D, Bloch D A, Bole G G, et al. Development of clinical criteria for osteoarthritis. F Rheumatol 1987; 14 (suppl 1): 3-6.

22 Sokoloff $\mathbf{L}$. Osteoarthritis as a remodelling process. F Rheumatol 1987; 14 (suppl 14): 7-10.

23 Cushnaghan J, Dieppe P. A long term study of 500 patients with 'osteoarthritis' (OA): disease patterns [abstract]. $\mathrm{Br} \mathcal{F}$ Rheumatol 1988; 27 (suppl 1): 11.

24 Peyron J G. The epidemiology of osteoarthritis. In: Moskowitz R W, Howell D S, Goldberg V M, Mankin H J, eds. Osteoarthritis: diagnosis and management. Philadelphia, London: Saunders, 1984: 9-70.

25 Christiensen S B. Localisation of bone seeking agents in developing experimentally induced osteoarthritis in the knee joint of the rabbit. Scand $\mathcal{F}$ Rheumatol 1983; 12: 343-9.

26 McAlindon T E, McCrae F, Watt I, Dieppe P A. Correlation between scintigraphic patterns and magnetic resonance images in osteoarthritis of the knee [abstract]. $B r \mathcal{F}$ Rheumatol 1989; 28 (suppl 2): 8.

27 McCrae F C, Palmer M, Shouls J C, Watt I, Dieppe P. Scintigraphic assessment of synovial and bone responses after intra-articular yttrium ${ }^{6}$ therapy [abstract]. $\mathrm{Br} \mathcal{F}$ Rheumatol 1988; 27 (suppl 1): 23.

28. Dieppe P A, McCrae FC. Pain and pain relief in osteoarthritis. Hospital Update 1987; 13: 904-14. 